\title{
Wilfried Floeck/Ana García Martínez \\ Memoria y olvido entre bastidores: Guerra Civil y franquismo en el teatro español después de 1975
}

\section{Observaciones preliminares}

La ocupación crítica con los períodos difíciles de la historia reciente es un fenómeno transnacional que se puede observar desde algunas décadas en todos los campos de la cultura. Tiene que ver también con el auge de la teoría de las culturas de la memoria en las dos décadas pasadas. En la tradición de los estudios de Maurice Halbwachs, Pierre Nora y Jan y Aleida Assmann se han publicado en los últimos años varios estudios sobre la rememoración del pasado reciente en la literatura y el cine. El creciente interés por hacer memoria está asimismo en relación con el hecho de que los testigos oculares de las grandes catástrofes del siglo pasado (Segunda Guerra Mundial, Holocausto, Guerra Civil Española) vayan muriéndose y de que, por eso, la rememoración de esos acontecimientos tenga que realizarse a través de textos escritos, sea de carácter historiográfico o ficticio. En terminología de Jan Assmann $\left({ }^{2} 1997\right)$, podemos decir que la memoria comunicativa está transformándose en la memoria cultural por la que los hombres intentan recordar la historia, fijarla y trasmitirla a las generaciones futuras. Además, la generación de los nietos no está implicada de la misma manera que los testigos directos en los acontecimientos del pasado reciente y se les enfrenta, por eso, con más ingenuidad y objetividad (Aguilar Fernández 2008: 29ss.). Mucho más que el trabajo historiográfico, el trabajo de la memoria individual y colectiva se basa en la selección y construye la realidad histórica según sus propias circunstancias emocionales, ideológicas y sociales. Uno de los descubrimientos más importantes de Maurice Halbwachs es el condicionamiento social tanto de la memoria individual como de la colectiva.

Hoy en día conocemos igualmente la estrecha relación entre memoria e identidad. En las sociedades modernas, caracterizadas por la 
pluralidad de los discursos ideológicos y por la hibridación cultural, no existen identidades nacionales, sino identidades de grupos. La identidad colectiva de un grupo es, en gran parte, el resultado de su comprensión común del pasado. El trabajo de rememoración e interpretación del pasado ayuda a crear una identidad individual y colectiva y contribuye, al mismo tiempo, a comprender y explicar el presente. "Nos definimos por lo que recordamos y olvidamos colectivamente" (Assmann 1999: 63; Neumann 2005: 1ss.). Ciertamente, la represión -psicológicamente comprensible- de acontecimientos traumáticos puede resultar aceptable -y hasta terapéuticamente beneficiosa-, pero, a lo largo, ni los individuos ni los colectivos pueden sustraerse al proceso de la rememorización de su propio pasado sin arriesgar graves problemas de identidad. Además, las ciencias políticas han probado empíricamente "las nefastas consecuencias del pasado silenciado para la convivencia democrática" (Bernecker/Brinkmann 2006: 339).

En España, el interés por la recuperación de la memoria histórica no ha surgido hasta la última década, pero ha penetrado en los años pasados en todos los campos de la vida cultural. La promulgación de la Ley de Memoria Histórica de España a finales de $2007^{1}$ y los trámites recientes del juez Baltasar Garzón forman el punto culminante de esta evolución. En la transición y en los primeros años de la democracia la política del consenso y de la reconciliación -con la consecuencia del famoso 'pacto de silencio'- impidió en gran parte una discusión crítica tanto de la Guerra Civil como del franquismo en la opinión pública. $^{2}$ Sin embargo, en la literatura y el cine el pasado nacional reciente nunca fue un tema tabuizado (Aguilar Fernández 1996: 20). Mechthild Albert (1999) ha computado la existencia de 170 novelas sobre la Guerra Civil y el franquismo solo para la década entre 1975 y 1985 y David Rey (2003) habla de la producción de unas cien películas sobre este tema entre 1975 y 2002. El teatro, por su parte, ha apor-

1 El título auténtico de la ley reza: "Ley por la que se reconocen y amplían derechos y se establecen medidas a favor de quienes padecieron persecución y violencia durante la Guerra Civil y la Dictadura" (cf. Aguilar Fernández 2008: 86).

2 En los últimos años, la literatura sobre el pacto de silencio y la política del consenso de la transición ha aumentado mucho. Además de los varios estudios de Aguilar Fernández y Juliá cf. también Morán (1991); Macher (2002); Luengo (2004); Bernecker (2005); Bernecker/Brinkmann (2006: 229ss.); Brinkmann (2008). 
tado - a pesar de que haya perdido mucho de su antigua importancia en la cultura actual- unas sesenta obras sobre el tema entre 1975 y la actualidad. Solo durante los ocho años de la transición se crearon una buena docena de textos dramáticos sobre la Guerra Civil y la dictadura franquista. Al contrario del cine y, sobre todo, de la novela, en el teatro este tema se ha estudiado muy poco. En Gießen constituye un núcleo central de nuestra investigación de la que quisiéramos presentar algunos resultados en la presente contribución. ${ }^{3}$

Los textos literarios constituyen un medio privilegiado en la construcción de memorias e identidades colectivas. Contribuyen a esta construcción no solo por la configuración de los acontecimientos históricos y de los personajes dramáticos, sino también por procedimientos puramente estéticos, como la estructura de la acción ficticia, la semantización del espacio y la configuración particular del tiempo. Además, son capaces de ofrecer distintas versiones de la reconstrucción del pasado y diferentes modelos de rememoración e identidad. La literatura de la memoria, sobre todo, es capaz de construir modelos de memoria colectiva alternativos, que expongan visiones y experiencias marginales o suprimidas por el discurso oficial. Puede contribuir a la estabilización o a la deconstrucción de la memoria dominante y apoyar la formación de memorias particulares y marginales. De esta manera, los textos literarios contribuyen activamente al proceso dinámico de la construcción de la memoria e identidad colectivas de los distintos grupos de una sociedad (Nünning 2005: 49ss.; Neumann 2005: 119 ss.). Todas estas funciones de las ficciones de la memoria pueden encontrarse también en los textos de la transición que, de esta manera, prepararon el camino al auge general de la rememoración de la Guerra Civil y de la dictadura franquista desde los últimos años del siglo XX.

Es bien conocida $-\mathrm{y}$ se muestra también en varias contribuciones del presente volumen- la relación estrecha entre el proceso de la memoria y la narración. La rememorización se realiza a través del acto de la narración. Hacer memoria es narrar. Es una de las razones por las que la novela es el género literario predilecto de la memoria. Por otro lado, no puede sorprender el hecho que el teatro de la memoria muchas veces manifieste un carácter evidentemente narrativo. En obras

3 Un buen panorama del teatro de la transición se encuentra en Pérez (1993); de Toro/Floeck (1995: sobre todo 1-46); Aznar Soler (1996); Paco (2004). 
como El álbum familiar (1982), ${ }^{4}$ de José Luis Alonso de Santos, Yo fui actor cuando Franco (1990), de Ignacio Amestoy Egiguren, En igualdad de condiciones (1995), de Pilar Pombo, o Perfume de la memoria (1989/1999), de Miguel Murillo, los protagonistas cuentan sus memorias a sí mismos o a otros personajes. También en obras como Carta de amor (1998), de Fernando Arrabal, o Las manos (1999), de José Ramón Fernández, Yolanda Pallín y Javier G. Yagüe, la predominancia de la memoria narrada es obvia. Por otro lado, el teatro - por su doble carácter de texto dramático y texto escénicoposee rasgos particulares que lo distinguen de los géneros narrativos propiamente dichos. Entre ellos cuatro nos parecen de importancia primordial para la configuración del tema de la memoria: la rememorización en un acto colectivo en el edificio teatral, la representación directa y sin mediación narrativa, la simultaneidad espacio-visual de los hechos recordados y, sobre todo, la integración de todos los sentidos del espectador mediante la utilización de los signos teatrales no verbales.

En Las manos los actores sirven a los espectadores en una pausa del espectáculo bebidas y platos típicos de la época teatralizada; en El álbum familiar las fotografías y los otros objetos de memoria no solo se mencionan como en la novela El jinete polaco (1991), de Antonio Muñoz Molina, sino que los espectadores pueden verlos con sus propios ojos; en El arquitecto y el relojero (1999), de Jerónimo López Mozo, los objetos como la vieja Olivetti, los quince juegos de esposas o los miles de fichas con las fotos de los detenidos muestran no solo a los invitados de la inauguración del edificio restaurado de la antigua Casa de Correos de la Puerta del Sol, sino también a los espectadores, la función del mismo edificio bajo la dictadura de Franco; en Perfume de la memoria los espectadores pueden sentir el olor de las mimosas sobre el ataúd del padre que provoca en el hijo el proceso de una rememorización amarga; y en Imagina (2001), la segunda pieza de la Trilogía de la juventud de Fernández, Pallín y Yagüe, las canciones que marcan la atmósfera y el espíritu de la época representada no solo se citan como en El jinete polaco, sino que se oyen en la sala del tea-

4 Siempre que se mencione una obra por vez primera en este artículo, se indicará el año del estreno o, si se trata de una obra sin estrenar, el año de la publicación correspondiente. 
tro. Los cuatro aspectos contribuyen a crear en el acto de la representación teatral una atmósfera de autenticidad, de densidad y de impacto emocional. No es sorprendente que en la mayor parte de las obras las historias contadas, en parte, se teatralicen en forma de retrospectivas sobre el mismo escenario. El teatro de la memoria se caracteriza por su doble carácter dramático-teatral y narrativo -y también, en algunos casos como Carta de amor, de Fernando Arrabal, Père Lachaise (2002), de Itziar Pascual, o 2004 (Tres retratos, tres paisajes y una naturaleza muerta) (2004), de Carlos Marquerie- por su carácter poético-lírico. También el teatro se abre cada vez más a otros géneros.

\section{De la cultura del consenso a la revisión crítica}

El famoso 'pacto de silencio' no produjo nunca una amnesia colectiva. Todo lo contrario, en los años de la transición la producción de obras teatrales sobre la Guerra Civil y la dictadura franquista fue -con más de una docena de piezas- relativamente elevada. Pero los efectos de la cultura del consenso y de la política de la reconciliación que -en palabras de Santos Juliá (2004: 462)- vino a ser "como un relato que liquidaba todos los grandes relatos", no quedaron sin repercusión en los escenarios. En primer lugar, se puede constatar que los dramaturgos de la Generación Realista y los representantes del Nuevo Teatro Español y de sus adeptos más jóvenes, que bajo la dictadura franquista habían llevado una lucha difícil contra la censura, no pudieron alcanzar el éxito esperado después de la muerte de Franco. Alfonso Sastre -con excepción del drama histórico La sangre y la ceniza (1965)siguió sin estrenar. Las obras de López Mozo Guernica y Anarchía 36, escritas en 1969 y 1971, solo fueron estrenadas en 1989. Los dramas Última batalla en El Pardo (1976), de José María Rodríguez Méndez, que consistía en un diálogo entre los dos generales Francisco Franco y Segismundo Casado, y Como reses (1979), varios cuadros sobre la historia nacional desde la guerra de Marruecos hasta el final de la Guerra Civil, escritos por Luis Matilla y López Mozo, solo se estrenaron en 1991 y 1987, respectivamente. El drama Volverán banderas victoriosas (1977), que trata de la actitud complicada que los miembros de distintas generaciones de la transición muestran frente a la Guerra Civil, de Antonio Martínez Ballesteros, no se ha estrenado hasta hoy en día. En la mayoría de los casos, la falta de interés o de 
medios financieros impidió una realización escénica. Solo en el caso curioso de la obra de Albert Boadella La torna (1977) intervino la censura -todavía en vigor antes de la promulgación de la Constitución en 1978- a solicitud de los militares, y es bien sabido que Boadella solo pudo sustraerse a la detención por la huida a Francia.

Solo Antonio Buero Vallejo, ya bajo la dictadura franquista un dramaturgo emblemático, pudo estrenar sus antiguas y sus nuevas obras, pero él también tuvo que sufrir las consecuencias de la política de la reconciliación. Su drama Jueces en la noche (1979) que contiene una dura crítica de la desmemoria colectiva, de la ley de amnistía general de 1977, del oportunismo político y de la influencia de los franquistas y los representantes del nacionalcatolicismo conservador en el gobierno de la transición, fue estrenado en 1981, pero no fue recibido por la crítica teatral con mucho entusiasmo, lo que explica Mariano de Paco (2007: 34) por los efectos de la política del consenso. Por el contrario, obras que representaban el franquismo desde una perceptiva sainetesca y que propagaban como mensaje principal una condena de la guerra en general -como Historia de unos cuantos (1971), de Rodríguez Méndez- pudieron estrenarse sin problemas en los años de la transición. Lo mismo vale también para obras de los dramaturgos nuevos que criticaron tanto el franquismo como el oportunismo político de la transición desde una perspectiva satírico-paródica -como en el caso de Tu estás loco, Briones (1978), de Fermín Cabal- o desde una perspectiva subjetiva y puramente privada -como en El álbum familiar, de Alonso de Santos (Floeck 2006: 194-198). La obra con más éxito fue, sin embargo, Las bicicletas son para el verano (1982), de Fernando Fernán-Gómez, cuya modelación de la Guerra Civil desde la perspectiva privada de los miembros de dos familias de la pequeña y media burguesía y cuyo alegato en favor de la paz y de la reconciliación de los dos bandos correspondía perfectamente a la política del consenso de la transición (Floeck 2006: 192-194).

Curiosamente, en los primeros años del gobierno socialista no se estrenó ninguna obra teatral sobre la Guerra Civil y la dictadura franquista. La situación cambió solo con el inmenso éxito de ;Ay, Carmela!, de José Sanchis Sinisterra, en 1987, cuyo efecto todavía aumentó por la versión cinematográfica de Carlos Saura tres años más tarde. Sanchis había escrito su drama en 1986 con ocasión del cincuentenario del alzamiento militar de 1936, para recordar las consecuencias de 
este trágico acontecimiento nacional (Sanchis Sinisterra 1991: 136). Con esta obra Sanchis se dirige contra el proceso de la desmemorización y utiliza el teatro conscientemente como medio de la rememoración. Como la protagonista reconstruye a través del acto de rememoración su identidad individual, la sociedad española podrá reconstruir su identidad colectiva, enfrentándose con la realidad de su pasado traumático. ;Ay, Carmela! es una obra contra el olvido y el 'pacto de silencio' de la transición (Aznar 1990: 254; Floeck 2006: 198-204). A través de Carmela Sanchis Sinisterra tematiza directamente la política del olvido y de la desmemoria dejándola fundar en "el otro mundo" un club "para hacer memoria", "porque los vivos", como explica a Paulino, "en cuanto tenéis la panza llena y os ponéis corbata, lo olvidáis todo" (Sanchis Sinisterra 1991: 261).

Con iAy, Carmela! empieza en el teatro español no solo el boom de la recuperación de la memoria, sino también el proceso de una revisión crítica de la historia nacional reciente en el teatro español actual. Desde 1987 se han estrenado en España más de 40 obras sobre la Guerra Civil y la dictadura franquista. Entre sus autores figuran gran parte de los dramaturgos más conocidos de la España democrática como Fernando Arrabal, Jerónimo López Mozo, José Luis Alonso de Santos, Fermín Cabal, José Sanchis Sinisterra, Ignacio Amestoy, José Ramón Fernández, Juan Mayorga, Itziar Pascual, Carlos Marquerie o Laila Ripoll.

\section{Del drama histórico al teatro de la memoria}

Nos limitaremos a enumerar algunos aspectos que distinguen estas obras del antiguo modelo del drama histórico tal como Buero Vallejo lo creara a finales de los años cincuenta. José Sanchis Sinisterra fue también el primero en proponer la noción de "teatro de la memoria" para este nuevo modelo dramático. Sus rasgos específicos se parecen no solo a los que Mechthild Albert había elaborado ya en 1999 para la novela de la memoria, sino también a las características ideológicas y estéticas de la postmodernidad. Estas características pueden resumirse en una tendencia a la despolitización, a la plasmación multiperspectivista, a la subjetivización de la perspectiva, a la fragmentación y estructura abierta de la acción dramática, a la complejidad de las estructuras espacio-temporales y a la pluralidad de los lenguajes dramatúr- 
gicos. El teatro de la memoria muestra su preocupación por el pasado nacional y la reconstrucción de una identidad colectiva, pero rechaza cualquier tipo de comprensión totalitarista de la historia y se dirige contra la visión maniqueísta de la generación anterior dejando al lector/espectador la tarea de participar activamente en la construcción de un sentido. Es un teatro de la duda que se hace preguntas sin dar soluciones totalitaristas. Pero, a pesar de su escepticismo ideológico y su carácter lúdico, manifiesta un auténtico compromiso ético frente a la historia reciente, que sirve a los autores para comprender su presente y construir un futuro mejor. Sobre todo, lo que caracteriza tanto la novela como el teatro de la memoria es la profunda reflexión metaficcional de las posibilidades y del proceso de reconstrucción de la realidad pasada. Los autores muestran a sus protagonistas en el difícil intento de hacer memoria de su propio pasado para reafirmar o reconstruir de esta manera su propia identidad personal. De la multitud de las memorias e identidades individuales nacen la memoria y la identidad colectivas que dan a una sociedad la posibilidad de construir su propio futuro y de evitar caer en la repetición de su propio pasado.

\section{El corpus: pluralidad de temas y autores}

Después de haber resaltado el alto grado de entrelazamiento del teatro de la memoria en el panorama memorial de la España democrática y de haber esbozado los rasgos más característicos del discurso memorialístico teatral, cabe adentrarnos en una descripción más detallada del corpus en cuestión. Contamos alrededor de sesenta obras, todas escritas o estrenadas después de 1975 y en lengua castellana, ${ }^{5}$ que evocan los dos capítulos más oscuros y polémicos de la historia reciente de España: la Guerra Civil y el franquismo. Antes de llevar a cabo una presentación cronológico-cuantitativa, nos interesa indagar en dos cuestiones relacionadas con el corpus, es decir, por una parte, en qué medida es de importancia la selección del período histórico y, por otra, hasta qué punto juega un papel el género del autor.

5 Textos dramáticos en vasco, catalán o gallego -como Quan la ràdio parlava de Franco (1979/1980), de Josep María, Passio: Final d'estiu amb tempesta (1992), de Francesc Lucchetti, Un bou ha mort Manolete (2003), de Llorenç Capellà, $O$ heroe (2005), de Manuel Rivas- no han podido ser considerados. El específico estudio del teatro de la memoria en las lenguas regionales españolas sería, sin lugar a dudas, un desiderátum de alto interés. 
En cuanto a las épocas históricas presentadas en los dramas, es imposible hallar un esquema específico en el corpus, las combinaciones temáticas destacan por su carácter múltiple y heterogéneo: más de la mitad de las obras nos habla de la contienda fratricida al igual que más de la mitad del pasado dictatorial, aproximadamente una tercera parte trata estas dos épocas históricas al mismo tiempo. El período de la transición y/o de la actualidad aparece, además, en casi el cincuenta por ciento de los casos, introduciendo así un nivel temporal de partida o referencia desde el cual se inicia, por ejemplo, el viaje al pasado de un protagonista-narrador, un viaje memorialístico que desemboca en la escenificación de los recuerdos, tan típica del memory play. ${ }^{6} \mathrm{Ni}$ que decir tiene que, en los dramas sobre el franquismo, la dicotomía entre el bando vencedor y el vencido es omnipresente; no obstante, la gran mayoría de los textos dramáticos retoma temas, contenidos y problemas de los oponentes y las víctimas franquistas, reivindicando aquellas memorias que fueron marginadas y silenciadas durante cuarenta años. Parece salir a la luz, en el discurso dramático-teatral, una falta de legitimación para escribir y llevar a escena ficciones memorialísticas presentadas desde la perspectiva y la voz de partidarios, agresores o verdugos del régimen. Aquellas pocas obras que adoptan esta perspectiva ponen de relieve, sobre todo, el carácter desfasado al igual que el fracaso de la ideología franquista en tiempos democráticos. En este contexto, podemos citar el ya mencionado ejemplo de Jueces en la noche, de Buero Vallejo; Tú estás loco, Briones, de Fermín Cabal; o Trampa para pájaros ${ }^{7}$ (1990), de José Alonso de Santos; la rebelión de los protagonistas de estas últimas dos piezas -en el primer caso un fiel seguidor del antiguo régimen, en el segundo caso, un policia edu-

6 El memory play constituye un súbgenero dramático que, según una definición de Brian Richardson, es "a partially enacted homodiegetic narrative in which the narrator is also a participant in the events he or she recounts and enacts" (Richardson 2001: 682). Por lo tanto, este término enfatiza, ante todo, a nivel formal una determinada composición dramática y no rivaliza, en ningún momento, con nuestro término genérico del teatro de la memoria. Entre los memory plays más conocidos figuran, por ejemplo, Travesties, de Tom Stoppard, The Glass Menagerie, de Tennesse Williams, Old times, de Harold Pinter, o Krapp's Last Tape, de Samuel Beckett.

7 La obra acaba de reestrenarse bajo la dirección del proprio Alonso de Santos con Juan Alberto López y Manuel Bandera, el 30 de enero de 2009, en el Teatro Alameda, de Málaga. 
cado y formado en la época franquista-, acaba con el desenlace mortal de ambos.

Si arriesgamos otra mirada escudriñadora al corpus, considerando esta vez cuestiones de género, nos revelará que las dramaturgas y sus obras ocupan aproximadamente el veinte por ciento de las obras registradas y de los veintisiete autores en total, contando las dos colaboraciones entre ambos sexos en la Trilogía de la juventud y Presas (2005), de Ignacio del Moral y Verónica Fernández. La práctica teatral confirma, pues, la tesis de que, como en la producción dramática en general, el teatro de la memoria en el caso concreto de España ha sido y sigue siendo un género de conotaciones prioritariamente masculinas, que no incita particularmente a las (jóvenes) dramaturgas a buscar una voz explícitamente femenina en el espacio teatral. A nivel temático, si bien hay ciertas obras de (co-)autoría femenina donde predominan las protagonistas -como en En igualdad de condiciones, de Pombo; Presas, de Moral/Fernández; Las republicanas (1984), de Teresa Gracia; o El día más feliz de mi vida (2004), de Laila Ripoll-, tenemos que admitir que existen igualmente obras con un reparto más equilibrado (por ejemplo, Trilogía de la juventud (2001ss.), de Fernández/Pallín/ Yagüe; Père Lachaise, de Pascual; Que nos quiten lo bailao (2004), de Laila Ripoll). Es más, no son pocas las obras de dramaturgos masculinos que escenifican las historias o memorias de protagonistas y personajes femeninos, lo que es el caso en Pasionaria (1994), de Ignacio Amnestoy Egiguren; Soliloquio de grillos (2003), de Juan Copete o Entrañas (2005), de Diego Lorca y Pako Merino. Dejando aparte quizá Las mujeres caminaron con el fuego del siglo (1982), de Lidia Falcón o En igualdad de condiciones, de Pilar Pombo, "en la que se habla de condición femenina, de tolerencia y de amistad entre dos mujeres muy distintas, con el telón de fondo de la guerra civil española de 1936" (Serrano 1999), no se percibe un especial afán de tocar explícitamente cuestiones de género. El teatro de la memoria de autoría femenina parece, pues, negarse a limitarse a representar únicamente temas estrictamente 'femeninos'.

A nivel estético, las dramaturgas destacan, igual que sus coetáneos, sobre todo por una gran variedad de lenguajes dramáticos. Dejando a Yolanda Pallín y Verónica Fernández aparte, tendríamos una amplia gama de discursos dramáticos de la memoria, unos rasgos estético-formales que, más que fruto del género femenino de las autoras, 
son particularidades personales que se reflejan en toda la obra dramática de cada una de ellas. Lo que tanto autoras como investigadores teatrales afirman para la producción dramática en general, cobra por lo tanto validez igualmente -o incluso aún más- para el discurso dramático de la memoria: resulta, por el momento, muy difícil encontrar un denominador común específicamente femenino en el teatro de la memoria. ${ }^{8}$

\section{Periodización}

Ante cualquier tipo de corpus surge tarde o temprano la cuestión de una posible clasificación de los textos correspondientes. Se ofrecen diversas formas de ordenar nuestros textos dramáticos, por ejemplo, según criterios temáticos, estético-formales, funcionales o cronológicos. En este caso, no son solo la heterogeneidad de los temas abordados, la pluralidad de los lenguajes dramáticos y la variedad de los potenciales memorialísticos los que desaconsejan una ordenación según estos parámetros, sino que también resulta harto reveladora la repartición cuantitativa de los estrenos y/o publicaciones de las obras a nivel cronológico, exponiendo claramente la interacción del discurso dramático-teatral con el panorama político-memorialístico. De ahí que podríamos distinguir tres fases que corresponderían, grosso modo, a la periodización político-gubernamental en la España democrática, con algunos cambios y leves desfases. Entre 1975 y 1982, se estrenaron en total el veinte por ciento de las obras del teatro de la memoria. Después de unos años en blanco no se reinicia, como ya se ha mencionado, la producción dramática sobre la memoria histórica hasta el estreno de ;Ay, Carmela! en 1987; en los siguientes tres años solo se dieron a conocer en total cuatro obras más. Las tres cuartas partes restantes del corpus corresponden a la última fase que, a diferencia del cambio político en 1996, ya comienza en 1993. En este período destaca el año 1999 con un total de nueve producciones teatrales, curiosamente de nuevo con un año de anterioridad en comparación con el comienzo del memory boom en España, lanzada por Emilio Silva y sus esfuerzos por promover las exhumaciones de las fosas comunes en el país. En 2004 y 2005, al inicio del primer mandado del actual presi-

8 Para indagar más en la temática de las dramaturgias femeninas en el teatro de la memoria cf. Floeck/Fritz/García Martínez (2008). 
dente Zapatero, se registra igualmente otro pequeño auge con diez obras estrenadas. De ahí que podamos alimentar la hipótesis general del teatro como medio y vehículo artístico de la memoria colectiva que cubre la carencia de políticas de la memoria por parte de las instituciones oficiales.

\subsection{Consenso e identificación (1975-1982)}

La primera fase, desde la muerte de Franco hasta la llegada de los socialistas al poder, ya ha sido caracterizada en el segundo capítulo de este artículo como un período en que los éxitos teatrales corresponden a la política oficial de la reconciliación y del consenso: mientras que el tono satírico-paródico (Fermín Cabal), subjetivo-onírico (José Luis Alonso de Santos) y privado-reconciliador (Fernando Fernán-Gómez) a la hora de abordar el pasado bélico y dictatorial sobre las tablas convencen tanto al público como a la crítica, no parece haber llegado todavía el momento para las pinceladas críticas al oportunismo político y a la permanencia de estructuras franquistas en la transición que nos ofrece Buero Vallejo con su Jueces en la noche. A nivel temático, predominan, por una parte, la presentación de las influencias de la Guerra Civil y de la dictadura en la vida privada y cotidiana de familias pequeño- y medioburguesas, o dicho en otras palabras, se evoca y se apela a las memorias familiares, aquel único refugio donde pudieron sobrevivir los recuerdos de los vencidos. Por otra parte, el género biográfico goza de cierto interés, llevando a escena las historias, salpicadas con elementos ficcionales, de la vida de personajes famosos como de Nicolás Franco (por Salóm) o García Lorca (por Rial y PírizCarbonell). Una voz explícitamente femenina y feminista se alza con la ya mencionada obra Las mujeres caminaron con el fuego del siglo, de Lidia Falcón, un recorrido, con tintes musicales, por el tema de la condición de las mujeres, cruzado con la problemática de las clases sociales, en la Ciudad Condal en el siglo XX que cierra justamente el 14 de abril de 1981.

A nivel estético-formal, resulta revelador que nos encontramos con casi toda la gama de posibles modos de presentación dramáticos: en algunas obras -como en los dramas de Fernán-Gómez y Salómimpera la representación escénica en su forma pura; otros dramas optan por una concepción compuesta por un marco temporal extradiegé- 
tico en el presente y la escenificación intradiegética de las memorias $\mathrm{del} / \mathrm{de}$ la protagonista, una concepción, típica del memory play, que pone de relieve la importancia de la referencia al presente correspondiente para todo proceso memorial. Este juego con diferentes niveles temporales y saltos retrospectivos no siempre está tan claramente marcado como en el caso de la obra de la única dramaturga de esta fase; parece existir ante todo un especial interés por experimentar con las posibilidades de representar teatralmente procesos de conciencia (Buero Vallejo), de sueños (Alonso de Santos, Cabal) o de alucinaciones (Cabal). En cuanto al potencial y las funciones memorialísticas de esta fase, hallamos de nuevo un abanico amplio: desde la reivindicación de figuras emblemáticas anteriormente silenciadas y marginadas como la de Lorca, pasando por la función terapéutica que desempeñan los viajes hacia el pasado recordado por los personajes dramáticos, unos viajes hacia las memorias familiares que cobran un valor representativo, y de ahí identificatorio, en particular para la generación de los niños de la guerra, presentes en el público, hasta el papel afirmativo de la política de la transición, abogando por el consenso y la reconciliación también sobre las tablas.

\subsection{Crítica y reconciliación (1987-1990)}

La fase intermedia se abre, como ya hemos visto, con el éxito rotundo de iAy, Carmela!, de José Sanchis Sinisterra, en 1987; al mismo tiempo, es la etapa que abarca el menor número de obras sobre la memoria histórica. Sin embargo, representa, sin lugar a dudas, un importantísimo paso en la evolución del teatro de la memoria, puesto que rompe explícitamente con el 'pacto de silencio', al denunciar las políticas del olvido y del silencio y reivindicar la necesidad y el deber de la rememoración y del recuerdo. Merece la pena volver a aquel club que Carmela, protagonista en el drama de Sanchis, quiere fundar en el otro mundo y profundizar en sus objetivos:

Carmela.- Pues para hacer memoria. [...] Sí: para contarnos todo lo que pasó, y por qué, y quién hizo esto, y qué dijo aquél...

Paulino.- ¿Para qué?

Carmela.- Para recordarlo todo.

Paulino.- ¿A quién?

Carmela.- A nosostros... y a los que vayáis llegando [al otro mundo]...

(Sanchis Sinisterra 1991: 261). 
Si bien queda patente, en esta cita, el afán de luchar contra el silencio y de rescatar los contenidos de la memoria colectiva del olvido, y todo esto mediante la narración y el recuerdo llevados a cabo en el seno de una comunidad -o sea del "club"-, resulta reveladora la absoluta falta de cualquier indicio que nos pudiera guiar hacia la opción de exigir reparaciones morales, económicas o jurídicas o incluso de dar rienda suelta a actitudes vengativas. Más que una comisión de la verdad, el club de la memoria ideado por Paulino representa una comisión de la reconciliación, un lugar donde la voluntad de comprender y dar sentido a lo ocurrido en el pasado es fruto de la necesidad básica del ser humano de hacer memoria, una necesidad indispensable para consolidar una comunidad y para garantizar la transmisión de conocimientos a nivel intergeneracional. Por lo tanto, sí a la crítica y ruptura con el 'pacto de silencio', pero al mismo tiempo también sí al discurso del consenso y de la reconciliación que resuena como leitmotiv en casi todas las obras del teatro de la memoria. Este enfoque crítico y reivindicativo subyace igualmente en las demás obras de los tardíos ochenta, menos quizá en Guernica y después (1990), de Francisco Torres Monreal, la que presenta una visión festiva y pictórica de las obras de Picasso con especial atención al cuadro dedicado al bombardeo de Guernica, más marcadamente en la ya mencionada Trampa para pájaros, de Alonso de Santos y, en particular, en Siete hombres buenos (1990), de Juan Mayorga, una ficción sobre el gobierno republicano en el exilio en tono paródico-satírico. De especial interés es, en este contexto, la primera parte Perfume de mimosas (1989) que, junto con la segunda parte El pájaro de plata (1999), compone la bilogía Perfume de la memoria, del extremeño Miguel Murillo (ambas publicadas en una sóla edición en 2001). Aquí ya se adelanta, en cierta medida, lo que será una de las grandes líneas de la última fase: las memorias de determinados grupos y colectivos marginados y silenciados durante el franquismo. En este caso concreto, se cruzan el tema de la memoria histórica y la identidad homosexual en tiempos dictatoriales, aunque este memory play no tematiza tanto "[1]a represión estatal de los homosexuales de antaño [...], es más bien la opresión identitaria ejercida por las estructuras familiares la que es denunciada sobre las tablas" (García Martínez 2008: 293). El protagonista Víctor, de adulto una cantante y transformista existosa, emprende un viaje al pasado familiar y logra finalmente superar a los fantasmas opresores de anta- 
ño, una victoria memorialística e identitaria que da a este proyecto una nota reconciliadora y esperanzadora.

\subsection{Contra-memorias, post-memoria y meta-memoria (1993-hoy)}

La producción dramática ha conocido, en esta última fase, una verdadera explosión de obras que pueden cobijarse bajo el alero del teatro de la memoria, una explosión dramático-teatral que anticipa en los años 90 el posterior boom de la memoria que invadirá los discursos públicos y políticos a partir del nuevo milenio. Como ya se ha aludido en la descripción de la fase bisagra, perdura y se intensifica la tendencia hacia un teatro comprometido que reivindica, abiertamente, los procesos y las necesidades de la memoria histórica, minando, de esta manera, el 'pacto de silencio', al menos en y desde el ámbito literarioteatral. En las casi cuarenta obras, de las que, lógicamente, no nos podemos ocupar detalladamente en este artículo, destacan dos coordenadas fundamentales. Por una parte, asaltan nuevos agentes memorialísticos los escenarios, es decir cobran mayor presencia las víctimas colectivas e individuales del franquismo al igual que la generación de los nietos, crecidos y educados en la democracia. Por otra, podemos observar cada vez más obras del teatro de la memoria que reflexionan sobre los problemas y los obstáculos, sobre los límites y las posibilidades inherentes al funcionamiento y los procesos de la memoria histórica.

Empecemos con el primer cambio que se patentiza en los personajes dramáticos. En el centro de esta fase, hallamos, en primer lugar, las voces de las víctimas colectivas, aquellas víctimas torturadas, perseguidas y silenciadas por el régimen franquista: como, por ejemplo, las mujeres en las cárceles franquistas en Presas o En igualdad de condiciones; los huérfanos en los hogares del Auxilio Social en Los niños perdidos (2005b), de Laila Ripoll; los muertos anónimos en las fosas comunes en Soliloquio de grillos; o exiliados, topos y víctimas del régimen en Terror y miseria en el primer franquismo (2002), de José Sanchis Sinisterra. Estos textos, que albergan las contra-memorias franquistas, se caracterizan por una gran pluralidad de lenguajes dramáticos: desde el juego complejo con niveles temporales en las obras de Pombo y Copete hasta las estructuras corales y fragmentadas en Sanchis y del Moral, desde la escenificación de la conciencia y de la 
memoria del protagonista en Los niños perdidos hasta la representación ilusionista de la acción dramática en Presas. El denominador común de estas obras está, a nuestro parecer, no solo en la función didáctica de informar al público español sobre estos 'capítulos oscuros' de la historia reciente nacional. Es más, hay un posicionamiento claramente comprometido, un compromiso ético que lucha contra la desmemoria, reivindicando una mayor presencia y una rehabilitación -al menos moral- de la memoria colectiva de los vencidos en el discurso memorialístico oficial en España.

Como otra innovación a nivel de los agentes memoriales, toma, en segundo lugar, el relevo la generación de los nietos, es decir las jóvenes generaciones de la España democrática. Aquellos representantes formarían parte de lo que Marianne Hirsch ha denominado postmemory. Este concepto -y por lo tanto también los personajes dramáticos en cuestión- se distinguen de los testigos contemporáneos por su distancia generacional y por haber tenido un contacto no directo, sino ya mediato con el pasado reciente. ${ }^{9}$ En muchos de los textos dramáticos de esta fase nos encontramos con protagonistas jóvenes que vuelven la mirada hacia el pasado reciente, buscando sus raíces identitarias, con el fin de obtener una mayor comprensión de la sociedad y realidad contemporáneas. Este camino se suele concretizar en una búsqueda, una búsqueda -a veces con tintes nostálgicos- del abuelo republicano, como en Père Lachaise y en Entrañas, o en una indagación sobre la represión de un grupo de republicanos en El jardín quemado (1997), de Juan Mayorga. Durante estos viajes hacia atrás, el pasado invade el presente, incorporando a los muertos como personajes-fantasmas, evocando espacios -en términos de Foucault- heterotópicos ${ }^{10}$ como el cementerio (Père Lachaise) o la psiquiatría (El jardín quemado) y también derrumbando a veces la cuarta pared en diversos juegos metateatrales.

Aparte de estos nuevos agentes memoriales, se advierten, a nivel temático, igualmente ciertos matices nuevos, sin que se abandone la

9 Dice Hirsch (2002: 22): "In my reading, postmemory is distinguished from memory by generational distance and from history by deep personal connection. Postmemory is a powerful and very particular form of memory precisely because its connection to its object or source is mediated not through recollection but through an imaginative investment and creation."

10 Para más información sobre el concepto de las 'heterotopías' cf. Foucault (1967). 
modelación de cuestiones memorialísticas de índole más 'clásico', como, por ejemplo, historias biográficas (por ejemplo, las obras de Ignacio Amestoy Eguiguren sobre La Pasionaria y Dionisio Ridruejo), acontecimientos y vivencias de la Guerra Civil (por ejemplo, Misión al pueblo desierto (1999), de Buero Vallejo; Armengol (2005), de Miguel Murillo), el exilio (por ejemplo, Que nos quiten lo bailao o el proyecto Guardo la llave (1999) de Fernández), la vida cotidiana bajo la dictadura (por ejemplo, Las manos o el gran éxito en el sector comercial El florido pensil (1996), basado en la obra homónima de Andrés Sopeña Monsalve) o, curiosamente, siguiendo el camino emprendido por iAy, Carmela!, la vida de los artistas en tiempos dictatoriales (por ejemplo, El olvido está lleno de memoria (2003), de Jerónimo López Mozo). Sin embargo, muchos ejemplos no constituyen tanto obras donde predomina la representación artística de la Guerra Civil o el franquismo en sí, sino que constituyen más bien dramas sobre el recuerdo del enfrentamiento fratricida y de la época dictatorial visto desde el presente, unos dramas memorialísticos donde la plasmación de diferentes niveles temporales cobra un papel importantísimo.

Se tematizan, pues, por un lado, problemas y obstáculos que la generación de los nietos tiene que abatir al rebuscar en tiempos pasados: la protagonista de Entrañas, una joven catalana treintañera que acaba de recibir la noticia de que espera un hijo, decide, por ejemplo, lanzarse a la búsqueda del destino que sufrió su abuelo republicano, desaparecido durante la Guerra Civil, y tropieza con las cortapisas impuestas por las fastidiosas tramitaciones de los archivos en Ávila y Salamanca. Por otro lado, cuestiones específicas de las políticas de la memoria conquistan igualmente el escenario, así en El arquitecto y el relojero, de Jerónimo López Mozo, donde el edificio del reloj de la Puerta del Sol y su rehabilitación se convierte en el lugar y el objeto de un conflicto ficticio entre un veterano relojero y un arquitecto moderno, representantes de las dos posturas opuestas, la memoria y el olvido. El volcán de la pena escupe llanto, una pieza de teatro breve de Alberto Miralles, publicada en 1998 y sin estrenar hasta la actualidad, revela cómo los sectores políticos instrumentalizan la memoria de un maestro al que le han dado el 'paseíllo' durante la Guerra Civil, vilipendiando o enalteciendo su recuerdo, según sus intereses. Estos y muchos ejemplos más constituyen un tipo de teatro que queremos llamar 'meta-memorialístico', ya que pone en escena, además de la mera 
representación del pasado recordado, el hecho mismo de recordar y los problemas resultantes, pues la meta-memoria es la función que la memoria desarrolla al autopresentarse, al reflexionar sobre sí misma y sobre las estrategias que se utilizan para recordar u olvidar a nivel individual y colectivo.

\section{Conclusión}

En un primer paso, hemos mostrado en qué medida el general auge de las teorías de la memoria y la globalización del recuerdo asaltan la sociedad española contemporánea, contribuyendo de ese manera, además de otros factores específicamentes peninsulares, al boom de la memoria en España. En el ámbito de la literatura de la memoria, hemos demostrado cómo confluyen elementos específicamente narrativos y específicamente dramático-teatrales en el teatro de la memoria y cómo convierten, así, el teatro en un lugar privilegiado para la formación y la reflexión sobre las memorias individuales y colectivas. De ese modo, se convierte el teatro de la memoria en una respuesta a la ausencia de políticas oficiales de la memoria en España, una respuesta estético-artística teñida de compromiso ético.

En un segundo paso, hemos perfilado las grandes líneas de las tres diferentes fases por las que pasa el teatro de la memoria desde la muerte de Franco: grosso modo, partiendo de la narración dramática de las memorias familiares e individuales así como del cumplimiento de los lemas del consenso y la reconciliación en la primera fase de la transición, pasamos por una revisión crítica del silencio oficial en la segunda fase bisagra, para llegar finalmente al apogeo donde no solo aparecen las voces de las contra-memorias franquistas y de las nuevas generaciones, sino que también se abordan cuestiones meta-memorialísticas.

Lo que Ulrich Winter afirma acerca de la revisión estética del pasado en la cultura memorativa española en general, es también aplicable, en gran medida, al discurso del teatro de la memoria: además de la falta de sentimiento de culpabilidad -aquí tendríamos una gran diferencia con el caso alemán-, sería sobre todo esa "mezcla de fatalismo lleno de humor y nostalgia, de horror y distancia crítica, de ironía y 
pedagogía"11 (Winter 2004: 632) la que determina lo específicamente español del discurso estético de la memoria. En lo que concierne el discurso dramático, podríamos añadir todavía, como tres claves más, los elementos narrativos, el Leitmotiv de la reconciliación y una visión altamente positiva del potencial memorativo que se atribuye a los procesos memoriales a nivel individual y colectivo. Esta visión positiva se traduce dramatúrgicamente en los happyends ofrecidos por la mayoría de las obras, mientras que solo en las obras de Mayorga y de Fernando Arrabal se pone en tela de juicio ese potencial memorativo. Lo que llama, además, la atención es que en el teatro de la memoria está ausente casi por completo -salvo en los escasos casos mencionados- la visión de los vencedores. ¿Hasta qué punto podríamos hablar de un corsé memorial en el que se meten los dramaturgos a la hora de escribir sobre la memoria? Quizá, casi 35 años después de la muerte de Franco, sea simplemente todavía demasiado temprano para que la sociedad española pueda asumir una revisión verdaderamente equilibrada y normalizada del pasado reciente nacional, sin que se abran viejas cicatrices. Esperemos que, más temprano que tarde, se dé este próximo paso en la cultura de la memoria en la Península, tan necesario para una democracia estable, viva y plural, un paso que, seguramente, dejará también huella en la producción dramática española, introduciendo nuevos temas y lenguajes en el teatro de la memoria.

\section{Bibliografía}

\section{Textos dramáticos}

Alonso de Santos, José Luis ([1982] 1992): El álbum familiar. Bajarse al moro. Ed. de Andrés Amorós. Madrid: Espasa Calpe.

— ([1990] 1991): Trampa para pájaros. Madrid: Marsó-Velasco.

Amestoy Egiguren, Ignacio ([1990] 1993): Yo fui actor cuando Franco. Mañana aquí, a la misma hora. Pról. de César Oliva. Madrid: Fundamentos.

- (1994): Dionisio Ridruejo. Una pasión española. ¡No pasarán! Pasionaria. Pról. de César Oliva. Madrid: Fundamentos.

Arrabal, Fernando ([1998] 2004): Carta de amor. Vuela hacia Cecilia. Madrid: SGAE.

Boadella, Albert ([1977] 1978): “La torna”. En: Pipirijaina, separata, pp. 8-9.

11 Traducción de los autores. 
Buero Vallejo, Antonio ([1979] 1994): “Jueces en la noche. Misterio profano en dos partes". En: Buero Vallejo, Antonio: Obras completas. Vol. II. Ed. por Luis Iglesias Feijoo y Mariano de Paco. Madrid: Espasa Calpe, pp. 1619-1714.

- (1999): Misión al pueblo desierto. Madrid: Espasa-Calpe.

Cabal, Fermín ([1978] $\left.{ }^{2} 1987\right):$ Tú estás loco, Briones. Fuiste a ver a la abuela??? Vade retro! Madrid: Fundamentos.

Copete, Juan (2003): Soliloquio de grillos. Mérida: De La Luna Libros.

Falcón, Lidia (2002): "Las mujeres caminaron en el fuego del siglo". En: Falcón, Lidia: Teatro feminista. Ed. de John Gabriele. Madrid: Fundamentos, pp. 7-58.

Fernández, Verónica/Moral, Ignacio del ([2005] 2007): Presas. Madrid: Centro Dramático Nacional.

Fernández, José Ramón (ed.) ([1999] 2005): Guardo la llave. Memoria de un exilio. Madrid: Teatro del Astillero.

Fernández, José Ramón/Pallín, Yolanda/Yagüe, Javier G. ([1999] 2001ss.). Trilogía de juventud. I: Las manos. Madrid: SGAE, 2001. II: Imagina. Madrid: SGAE, 2002. III: 24/7 (veinticuatrohorasaldiasietediasalasemana). En: $<$ www.cuartapared.com> (31.05.2009).

Fernán-Gómez, Fernando ([1982] $\left.{ }^{8} 1989\right)$ : Las bicicletas son para el verano. Ed. de Eduardo Haro Tecglen. Madrid: Espasa Calpe.

Gracia, Teresa (1984): Las republicanas. Valencia: Pre-Textos.

López Mozo, Jerónimo ([1969] 1975): “Guernica”. En: Estreno, 1, pp. 19-31.

- ([1978] 1978): “Anarchía 36”. En: Pipirijaina. Textos, 6, pp. 10-59.

- (2001): El arquitecto y el relojero. Madrid: ATT.

- (2003): El olvido está lleno de memoria. Madrid: ADE Teatro.

Lorca, Diego/Merino, Pako (2005): Entrañas. Manuscrito.

Marquerie, Carlos (2004): 2004 (Tres paisajes, tres retratos y una naturaleza muerta). Madrid: Contextos.

Martínez Ballesteros, Antonio ([1977] 1990): Volverán banderas victoriosas: obradocumento en dos actos divididos en cuatro cuadros. Madrid: Julia García Verdugo.

Matilla, Luis/López Mozo, Jerónimo ([1979] 1980): Como reses (Memoria de un Matadero). Madrid: Nuestra Cultura.

Mayorga, Juan (1990): "Siete hombres buenos". En: Instituto de la Juventud (ed.): Concurso de textos teatrales para jóvenes autores Marqués de Bradomín 1989. Madrid: Instituto de la Juventud, pp. 97-185.

- (2007): El jardín quemado. Introd. de Virtudes Serrano. Murcia: Universidad de Murcia.

Miralles, Alberto (1998): "El volcán de la pena escupe llanto". En: Miralles, Alberto: Teatro breve. Madrid: Fundamentos, pp. 139-159.

Murillo, Miguel ([1989/1999] 2001): Perfume de la memoria. Introd. de Gregorio de Torres Negrera. Murcia: Universidad de Murcia.

- (2006): Armengol. Madrid: Teatro Español. 
Pascual, Itziar (2003): Père Lachaise. Madrid: AAT.

Píriz-Carbonell, Lorenzo (1992): Federico. Una historia diferente. Murcia: Universidad de Murcia.

Pombo, Pilar ([1995] 1999): En igualdad de condiciones. Introd. de Carmen Resino. Murcia: Universidad de Murcia.

Rial, José Antonio (1983): “La muerte de García Lorca”. En: Pipirijaina, 23, pp. 73144.

Ripoll, Laila (2004): "El día más feliz de nuestra vida". En: Serrano, Virtudes (ed.): Teatro breve entre dos siglos. Madrid: Cátedra, pp. 407-421.

- ([2004] 2005a): "Que nos quiten lo bailao”. En: ADE Revista, 105, pp. 65-78.

- (2005b): “Los niños perdidos”. En: Primer Acto, 310, pp. 131-167.

Rodríguez Méndez, José María ([1971] 2005): “Historia de unos cuantos”. En: Rodríguez Méndez, José María: Teatro escogido. Vol. II. Madrid: ATT, pp. 173-227.

Salóm, Jaime (1981): El corto vuelo del gallo. Barcelona: Grijalbo.

Sanchis Sinisterra, José ([1987] 1991): Ñaque o de piojos y actores. ¡Ay, Carmela! Ed. por Manuel Aznar Soler. Madrid: Cátedra.

- (2003): Terror y miseria en el primer franquismo. Ed. de Milagros Sánchez Arnosi. Madrid: Cátedra.

Sopeña Monsalve, Andrés ([1996] 1994): El florido pensil. Barcelona: Crítica.

Torres Monreal, Francisco (2001): “Guernica y después”. En: Torres Monreal, Francisco: Baudelaire maldito y otras obras. Ed. de F. Cantalapiedra, Madrid: Fundamentos, pp. 133-149.

\section{Estudios críticos}

Aguilar Fernández, Paloma (1996): Memoria y olvido de la Guerra Civil. Madrid: Alianza.

- (2008): Politicas de la memoria y memorias de la politica. El caso español en perspectiva comparada. Madrid: Alianza.

Albert, Mechthild (1999): "La Guerra Civil y el franquismo en la novela desde 1975". En: Iberoamericana, 23, pp. 38-67.

Assmann, Aleida (1999): Erinnerungsräume. Formen und Wandlungen des kulturellen Gedächtnisses. München: Beck.

Assmann, Jan (21997): Das kulturelle Gedächtnis. Schrift, Erinnerung und politische Identität in frühen Hochkulturen. München: Beck.

Aznar Soler, Manuel (1990): “Grenztheater als Metatheater. José Sanchis Sinisterras Teatro Fronterizo: von Naque bis ;Ay, Carmela!". En: Floeck, Wilfried (ed.): Spanisches Theater im 20. Jahrhundert. Tübingen: Francke, pp. 233-255.

- (1996): "Teatro español y sociedad democrática (1975-1995)". En: Aznar Soler, Manuel (ed.): Veinte años de teatro y democracia en España (1975-1995). Barcelona: CITEC, pp. 9-31.

Bannasch, Bettina/Holm, Christiane (eds.) (2005): Erinnern und Erzählen. Der spanische Bürgerkrieg in der deutschen und spanischen Literatur und in den Bildmedien. Tübingen: Narr. 
Bernecker, Walther L. (2005): "Demokratisierung und Vergangenheitsaufarbeitung in Spanien". En: Bannasch, Bettina/Holm, Christiane (eds.): Erinnern und Erzählen. Der spanische Bürgerkrieg in der deutschen und spanischen Literatur und in den Bildmedien. Tübingen: Narr, pp. 9-23.

Bernecker, Walther L./Brinkmann, Sören (2006): Kampf der Erinnerungen. Der Spanische Bürgerkrieg in Politik und Gesellschaft 1936-2006. Fulda: Graswurzelrevolution.

Brinkmann, Sören (2008): "Die Rückkehr der Vergangenheit: Bürgerkrieg und Diktatur im öffentlichen Meinungsstreit". En: Bernecker, Walther L. (ed.): Spanien heute. Politik, Wirtschaft, Kultur. Frankfurt am Main: Vervuert, pp. 109-132.

Floeck, Wilfried (2006): "Del drama histórico al teatro de la memoria. Lucha contra el olvido y búsqueda de identidad en el teatro español reciente". En: Romera Castillo, José (ed.): Tendencias escénicas al inicio del siglo XXI. Madrid: Visor, pp. 185-202.

Floeck, Wilfried/Fritz, Herbert/García Martínez, Ana (eds.) (2008): Dramaturgias femeninas en el teatro español contemporáneo: entre pasado y presente. Hildesheim: Georg Olms.

Foucault, Michel (1967): "Des espaces autres. Hétérotopies“. En: <www.foucault. info/documents/heteroTopia/foucault.heteroTopia.fr.html> (31.05.2009). En alemán: Foucault, Michel (1991): “Andere Räume”. En: Barck, Karlheinz (ed.): Aisthesis. Wahrnehmung heute oder Perspektive einer anderen Ästhetik. Leipzig: Reclam, pp. 34-46.

García Martínez, Ana (2008): "Memorias disidentes: identidad homosexual y (re-) construcción del pasado en Perfume de la memoria, de Miguel Murillo". En: Barcarola, 71/72, pp. 283-295.

Halbwachs, Maurice (2002): La mémoire collective. Paris: Michel.

Hirsch, Marianne (2002): Family Frames: Photography, Narrative and Postmemory. Cambridge: Harvard University Press.

Humphrey, Richard (2003): "Literarische Gattung und Gedächtnis". En: Erll, Astrid/ Nünning, Ansgar (eds.): Gedächtniskonzepte der Literaturwissenschaft. Theoretische Grundlegung und Anwendungsperpektiven. Berlin: De Gruyter, pp. 73-95.

Juliá, Santos (2004): Historias de las Dos Españas. Madrid: Taurus.

López de Abiada, José Manuel (2004) (ed.): “Dossier: Memoria y transición española: historia, literatura, sociedad”. En: Iberoamericana, 15, pp. 81-154.

Luengo, Ana (2004): La encrucijada de la memoria. Berlin: Walter Frey.

Macher, Julia (2002): Verdrängung um der Versöhnung willen? Die geschichtspolitische Auseinandersetzung mit Bürgerkrieg und Franco-Diktatur in den letzten Jahren des friedlichen Übergangs von der Diktatur zur Demokratie in Spanien (1975-1978). Bonn: Friedrich-Ebert-Stiftung.

Morán, Gregorio (1991): El precio de la transición. Una interpretación diferente y radical del proceso que condujo a España de la dictadura a la democracia. Barcelona: Planeta.

Neumann, Birgit (2005): Erinnerung - Identität - Narration. Gattungstypologie und Funktionen kanadischer "Fictions of Memory". Berlin: De Gruyter. 
Nora, Pierre (1984ss.): Les lieux de mémoire. 7 vols. Paris: Gallimard.

Nünning, Ansgar (2005): "Literarische Geschichtsdarstellung: Theoretische. Grundlagen, fiktionale Privilegien, Gattungstypologie und Funktionen”. En: Bettina/ Holm, Christiane (eds.): Erinnern und Erzählen. Der spanische Bürgerkrieg in der deutschen und spanischen Literatur und in den Bildmedien. Tübingen: Narr, pp. 35-58.

Paco, Mariano de (2004): "El teatro español en la transición: ¿Una generación olvidada?". En: Anales de la Literatura Española, 17, pp. 145-158.

- (2007): “Jueces en la noche, de Buero Vallejo: contexto, texto y recepción”. En: Estreno, 33.1, pp. 29-37.

Pérez, Manuel (1993): "La escena madrileña en la transición política (1975-1982)". En: Teatro. Revista de Estudios Teatrales, 3-4 (número monográfico).

Rey, David (2003): "Die Franco-Ära in der medialen Geschichtskultur Spaniens. Bürgerkrieg und Diktatur in Kino und Fernsehen seit 1975". En: Jahrbuch für Europäische Geschichte, 4, pp. 113-159.

Richardson, Brian (2001): "Voice and Narration in Postmodern Drama". En: New Literary History, 32, 3, pp. 681-694.

Romera Castillo, José (ed.) (2003): Teatro y memoria en la segunda mitad del siglo XX. Madrid: Visor Libros.

Romera Castillo, José/Gutiérrez Carbajo, Francisco (eds.) (1999): Teatro histórico (1975-1998). Textos y representaciones. Madrid: Visor Libros.

Sanchis Sinisterra, José (2002): "Una propuesta del autor”. En: Terror y miseria en el primer franquismo de José Sanchis Sinisterra. Cuaderno pedagógico. Madrid: Teatro del Común, pp. 9-10.

Serrano, Virtudes (1999): "Dramaturgas españolas de fin de siglo". En: Matices, 21 (<www.matices.de/21/21sautor.htm>; 14.11.2010).

Toro, Alfonso de/Floeck, Wilfried (eds.) (1995): Teatro español contemporáneo. Autores y tendencias. Kassel: Reichenberger.

Winter, Ulrich ( $\left.{ }^{4} 2004\right)$ : "Spaniens Intellektuelle: Eine neue Diskussionskultur und die Debatte um Identitäten und 'Erinnerungsorte' (1976-2002)”. En: Bernecker, Walther L./Dirscherl, Klaus (eds.): Spanien heute. Politik - Wirtschaft - Kultur. Frankfurt am Main: Vervuert, pp. 631-655.

- (ed.) (2006): Lugares de memoria de la guerra civil y el franquismo. Representaciones literarias y visuales. Madrid/Frankfurt am Main: Iberoamericana/Vervuert. 